\title{
Monitoring ground deformation of eruption center by ground-based interferometric synthetic aperture radar (GB-InSAR): a case study during the 2015 phreatic eruption of Hakone volcano
}

\author{
Senro Kuraoka ${ }^{1^{*} \mathbb{D}}$, Yuichi Nakashima ${ }^{1}$, Ryosuke Doke ${ }^{2}$ and Kazutaka Mannen²
}

\begin{abstract}
We successfully monitored the ground deformation of an eruption center during the 2015 phreatic eruption of Hakone volcano, Japan, using ground-based interferometric synthetic aperture radar (GB-InSAR). GB-InSAR has been developed and applied over the past two decades and enables the frequent ( $<10 \mathrm{~min}$ ) aerial monitoring of surficial deformation of structures and slopes. We installed a GB-InSAR 4 days before the eruption of Hakone volcano on June 29, 2015, and monitored the ground deformation of an area where uplift was detected by a satellite InSAR. The ground deformation observed by the GB-InSAR began suddenly on the morning of June 29 almost coincident with the intrusion of hydrothermal fluid that was inferred by other geophysical observations. The hydrothermal crack is considered to have caused the eruption, which was known by an ash fall $5 \mathrm{~h}$ later. The GB-InSAR results indicated a significant uplifted area which is approximately $100 \mathrm{~m}$ in diameter, and new craters and fumaroles were created by the eruption in and around the area. The displacement reached up to a total of $45 \mathrm{~mm}$ until the evening of June 29 and continued at least until the morning of July 1. During our observation, the displacement rate decreased twice, and the timing of each decrease seemed to correspond to the formation of new conduits as implied from geophysical observations.
\end{abstract}

Keywords: GB-InSAR, Hakone volcano, Ground deformation, Phreatic eruption, Hydrothermal fluid

\section{Introduction}

A phreatic eruption is a volcanic explosion caused by confined steam and gas beneath the ground surface without the direct involvement of magma (Barberi et al. 1992). Generally, the volume erupted during this type of eruption is small, and only a limited area around the vent is affected; however, source vent areas often form major tourist destinations, such as Tongario National Park in New Zealand and Ontake in Japan, and such proximity to human activity sometimes results in tragedy. The

\footnotetext{
*Correspondence: a4982@n-koei.co.jp

${ }^{1}$ R\&D Center, Nippon Koei Co., Ltd., 2304 Inarihara, Tsukuba, Ibaraki Prefecture, Japan

Full list of author information is available at the end of the article
}

forecasting of phreatic eruptions is thus considered key to avoiding the loss of human life. However, the precursors to this type of eruption are, in most cases, subtle and inadequate since the level of available signal before an eruption can be same as observed during a quiescence period. To monitor and interpret the hydrothermal system beneath the volcano surface, coordinated observation of conventional methods, such as seismic and geodetic approaches, are important. In addition, we believe that new instruments to monitor disparate signals created by different hydrothermal processes could facilitate breakthroughs.

Based on an extensive review of previous studies, Barberi et al. (1992) indicated that some phreatic eruptions accompanied ground deformation as a precursor. 
However, Barberi et al. (1992) also notes that there were very few monitoring cases that have captured ground deformation. We consider InSAR to be a powerful method that provides areal coverage of the ground surface from a safe location during volcanic unrest. Following the satellite-based InSAR, Ground-based InSAR (GBInSAR) has been developed. The GB-InSAR enables frequent $(<10 \mathrm{~min}$ ) areal monitoring of ground deformation with resolutions ranging from several $\mathrm{mm}$ to tens of $\mathrm{mm}$ depending on the monitoring distance and atmospheric conditions. To date, GB-InSAR has been applied to monitor the movement of concrete structures, earth structures, and slopes from remote locations (e.g., Bozzano et al. 2008; Farina et al. 2013; Atzeni et al. 2015). Since 2011, GB-InSAR has been used to monitor the long-term movement of a large unstable lava dome of the Unzen volcano in Nagasaki Prefecture, Japan; however, this monitoring is rather a case of landslide monitoring, since the lava dome has remained volcanologically inactive after its formation by the 1990-1995 eruption (Satou et al. 2014).

We installed a GB-InSAR instrument such that the scanned area covers the central Owakudani area (COA) just 4 days before the 2015 eruption of Hakone volcano and continuously monitored the ground deformation associated with the phreatic eruptions until July 3 (Fig. 1). In this paper, we describe our instrumental setting, data processing procedure, and the time sequence of ground deformation of the eruption center before, during, and after the eruption.

\section{The 2015 eruption of Hakone volcano and installation of the GB-InSAR}

Hakone volcano is a caldera volcano located approximately $80 \mathrm{~km}$ west of Tokyo, the capital of Japan. Within the $11 \mathrm{~km}$ by $11 \mathrm{~km}$ caldera, a N-S-trending array of lava domes and small stratovolcanoes formed and are called the younger central cones. Near the northernmost part of the central cones, Kanmurigatake, an andesitic lava dome, formed approximately 3000 years ago. This is the newest edifice of the volcano, and on its eastern flank is Owakudani, the largest steaming area of the volcano.

Since the latest magmatic eruption that formed Kanmurigatake, several phreatic eruptions with erupted volumes on the order of $10^{5} \mathrm{~m}^{3}$ have been recognized based on geological investigation. Although the latest phreatic eruption was thought to have taken place in the thirteenth century, there is no historical record of phreatic eruption of the volcano.

In April 2015, a slight inflation of the volcano was observed by the GNSS network, and an earthquake swarm started within the caldera later that month. On May 3, a steam well (500 $\mathrm{m}$ in depth) in Owakudani, which was drilled to obtain steam to create artificial hot spring water, had an uncontrolled blowout. This intensification of steaming activity seems to have been caused by a pressure rise in the shallow hydrothermal system of the steaming area. Such a pressure rise in the hydrothermal system was also expressed by local uplifting (up to $6 \mathrm{~cm}$ in the area $<100 \mathrm{~m}$ in radius until May 7) around the steam well observed by satellite-based InSAR (Doke et al. 2015). Based on these observations, the local government of Hakone designated the area around the steam well as a 'no-entry zone' (Mannen et al. 2018). After late May, surface steaming activity became prominent within the uplifting area, and this observation also supports increased hydrothermal activity in this area. We thus assumed that the area around the steam well is the principal candidate for the eruption center in the future eruption.

An abrupt increase in the number of earthquakes and volcanic tremors occurred at 7:32 a.m. (Japan Standard Time in this paper; JST $=\mathrm{UTC}+9$ ) (Yukutake et al. 2017). The concurrently observed tilt change suggested formation of a NW-SE-trending crack near Owakudani (Honda et al. 2018). On the same day, volcanic ashfall started at approximately 12:30. At 16:02 on June 29, the first impulsive infrasonic wave was observed (Yukutake et al. 2017, 2018). Several impulsive waves were observed after that until the morning of June 1. The eruption seems to have continued until noon of July 1.

Four new craters and up to 20 fumaroles were created in the COA during the eruption (Mannen et al. 2015, 2018). The satellite-based InSAR detected localized uplifting at COA, using the interferometric pairs which were obtained before and after the eruption. The location of the pressure source was estimated to be at $80-90 \mathrm{~m}$ beneath the surface by inversion analysis of the observed ground deformation (Doke et al. 2018).

\section{Outline of the GB-InSAR}

The GB-InSAR used in this study comprises the hardware called IBIS-L and the data processing software called Guardian (version 3.0). These are produced by HEXAGON Geosystems. A detailed description of the system specification and the procedures can be found in previous studies (e.g., Bozzano et al. 2008).

The system uses stepped frequency continuous wave (SFCW) radar with discrete frequency modulation over the prescribed bandwidth. The central frequency and the bandwidth (B) of the system were set at $17.175 \mathrm{GHz}$ and $140 \mathrm{MHz}$, respectively. The wavelength corresponding to the central frequency was $17.5 \mathrm{~mm}$, and the effective isotropic radiated power was $26 \mathrm{dBm}(398 \mathrm{~mW})$, which conformed with the radio wave regulations in Japan.

The size of the pixel is defined by the range $(\Delta R)$ and cross-range resolutions $(\triangle \mathrm{CR})$ that are expressed in the radar coordinates (Fig. 2). The range resolution 


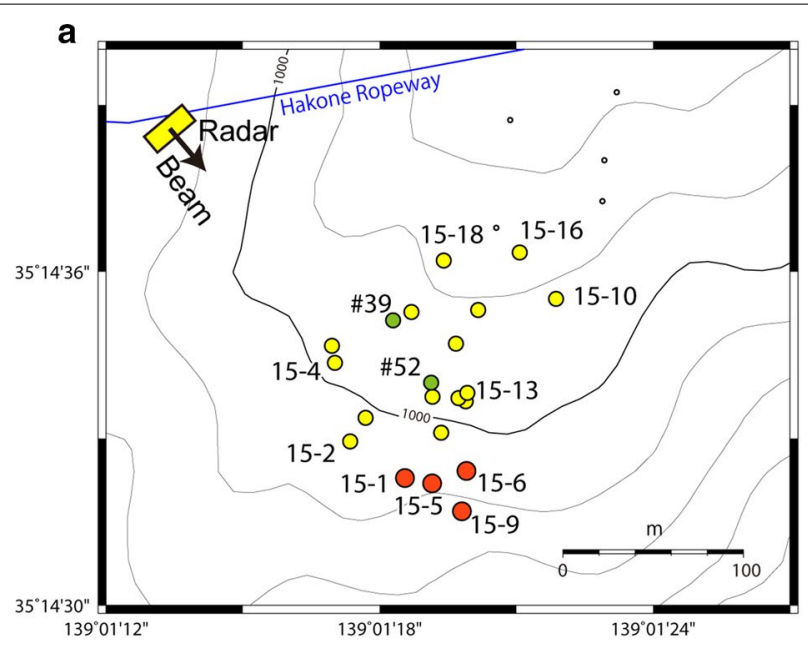

New craters formed during 2015 eruption

Newly formed fumaroles

Steam well blowouts during 2015 unrest

Other steam wells
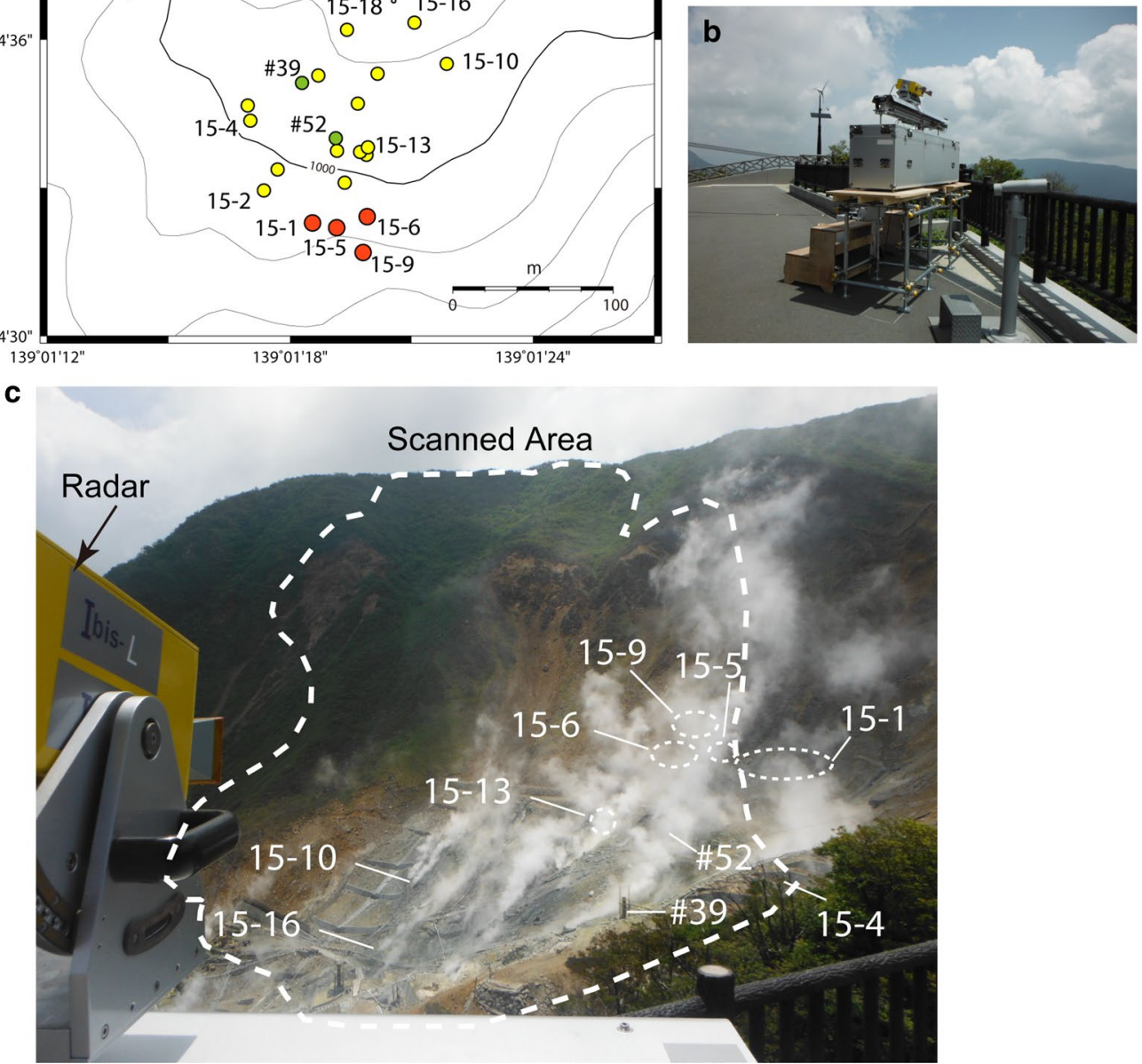

Fig. 1 Location and monitoring direction of the GB-InSAR. a Locations of new craters, new fumaroles, and steam wells that blew out in Owakudani area, $\mathbf{b}$ the GB-InSAR equipment installed in Owakudani, and $\mathbf{c}$ photograph showing the area scanned by the GB-InSAR radar. The names of craters and fumaroles are based on Mannen et al. (2018)

is determined by the bandwidth $B$ of the transmitted stepped-frequency signal and the speed of light $c$ as follows (e.g., Mazzanti et al. 2015):

$$
\Delta \mathrm{R}=\frac{c}{2 B}
$$

The range resolution is $1.07 \mathrm{~m}$ for the given wave characteristics set in this case. The cross-range (azimuth) resolution is directly related to the synthetic antenna length $L$ by:

$$
\Delta \mathrm{CR}=r \frac{\lambda}{2 L}=r \cdot \theta
$$

where $r$ is the distance between the target and the sensor, $L$ is the length of the scanner, $\lambda$ is the wavelength, and $\theta$ is the cross-range resolution in radians (e.g., Mazzanti et al. 2015). The cross-range resolution in radians is $4.4 \mathrm{mrad}$ for $\lambda=17.5 \mathrm{~mm}$ and $L=2.0 \mathrm{~m}$. The cross-range resolution in distance units is between 0.44 and $1.3 \mathrm{~m}$ for the scanning distance ranging from 100 to $300 \mathrm{~m}$.

The displacements in the range direction are related to the phase difference between the two radar images acquired at different times, as follows:

$$
\Delta \varphi=\frac{4 \pi}{\lambda}\left(\Delta d+\Delta d_{\mathrm{atm}}\right)+n
$$


where $\Delta \varphi$ is the phase difference between the two acquisitions, $\Delta d$ is the displacement in the range direction, $\Delta d_{\text {atm }}$ is the shift due to atmospheric effects, $n$ is the noise such as instrumental noise and vegetation effects (Monserrat et al. 2014). Atmospheric effects such as variations in humidity and temperature are the major components that must be removed to obtain the displacements. Two consecutive acquisitions are used to obtain one interferometry. Then unwrapping is performed to obtain the incremental displacement of the two consecutive acquisitions. The cumulative displacements are obtained by summation of the incremental displacements.

The displacements are computed for each pixel and are expressed in radar coordinates, whereas the digital elevation map (DEM) for viewing the results is in the Cartesian coordinate system. Hence, if the pixel of the radar coordinate is smaller than the grid size of the DEM, the displacement of the square grid of the DEM is the average of the displacements of the pixels that share the same square grid. Furthermore, the displacements are the component of the actual displacement in the range direction of the radar coordinates, and the component in the cross-range direction cannot be measured.

Following procedures, that are similar in principle to those of a satellite-based InSAR, are used in the software (Guardian 3.0) to remove the atmospherically induced phase variation prior to the computation of the relative displacements.

One of the main procedures is to generate the threedimensional mathematical plane that expresses the three-dimensional phase surface of the stationary area. This three-dimensional mathematical plane will be referred to as the correction plane hereafter. The pixels with good coherence in the hypothetical stationary area will be selected as the permanent scatterers (PS) for the atmospheric correction. During the initial 10 acquisitions, the software will automatically search the stationary PS points, assuming that $50-60 \%$ of the whole pixels are the stationary PS points. The phase variations of these PS points are assumed to be induced by the atmospheric effects, and the correction plane is fit to the phase surface. Then, the atmospheric components in the moving area are subtracted using this correction plane.

The correction plane is updated with time as the atmospheric conditions and movement of the ground surface changes with time. As the data acquisition proceeds, certain PS points in the hypothetical stationary area may be evaluated as moving (e.g., Rubén et al. 2014). The process will update the correction plane by differentiating the moving PS.

In these processes, it is difficult to generate a correction plane that perfectly matches the phase surface. Furthermore, the hypothetical stationary area is not necessarily the true motionless area but the whole area could be slowly moving. Hence, the resulting displacements are the magnitudes relative to those of the hypothetical stationary area and will be referred to as the 'relative displacements' in the following sections.

The accuracy of the relative displacements depends on the atmospheric environment, distance to targeted area, topographic features, and size of the moving area relative to the size of the stationary area. Monserrat et al. (2014) reviewed the accuracy of the GB-InSAR of different manufacturers and Atzeni et al. (2015) compared the displacements of the GB-InSAR, which is the same type as the one in this research, with those of a total station. These studies suggest that the accuracy of GB-InSAR is in the millimetric scale. However, the atmospheric environment of Owakudani was different from the conditions in these studies. Moreover, there were no other monitoring instruments in Owakudani to compare with the GBInSAR. Hence, we could not exactly evaluate the error bounds of the relative displacements of the case presented in this article. As will be mentioned later in this article, the authors calculated the standard deviations of the relative displacements of GB-InSAR before the earthquake swarm.
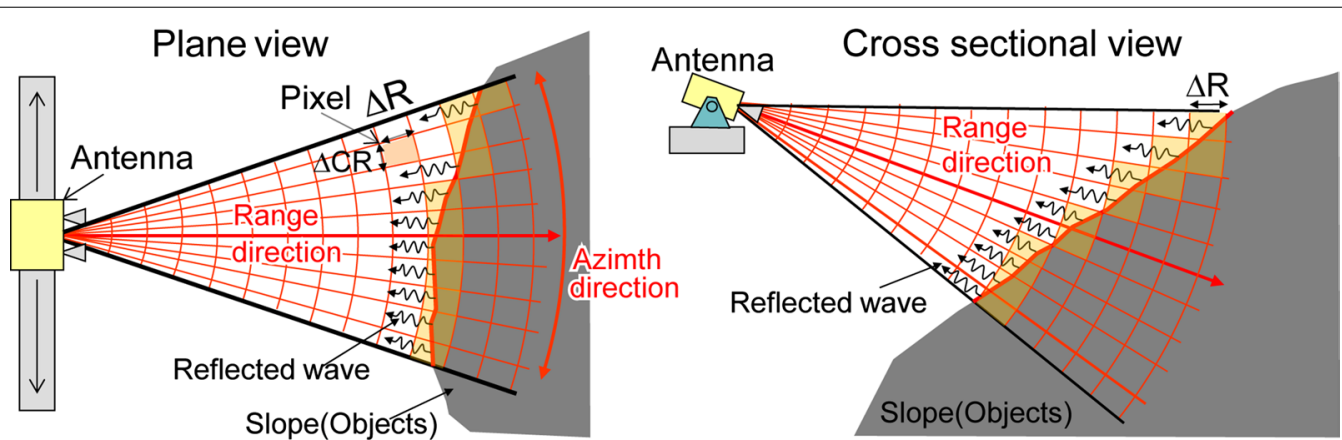

Fig. 2 Plane and cross-sectional views of radar coordinates and resolutions of the GB-InSAR with respect to a slope. $\triangle R$ and $\triangle C R$ are the range and cross-range resolutions, respectively 


\section{Monitoring procedures and results}

The instrument was installed near the Owakudani ropeway station, approximately $200 \mathrm{~m} \mathrm{NW}$ of the eruption center (Fig. 1). The sensor module with two antennas was approximately $2 \mathrm{~m}$ high above the surface of the observation platform overlooking the Owakudani Valley. The antennas were directed in southeast direction (130 degrees clockwise from North) dipping $15^{\circ}$ downward from horizontal.

The monitoring started at 10:20 on June 25, 2015, and continued until 9:26 on July 3, 2015, approximately 8 days. The scanning time interval was $7 \mathrm{~min}$ and $35 \mathrm{~s}$, that includes (1) $7 \mathrm{~min} 10 \mathrm{~s}$ for the antenna to perform scanning from the left end to the right end; (2) $10 \mathrm{~s}$ to return to the center; (3) $5 \mathrm{~s}$ to calibrate the antenna position; and (4) $10 \mathrm{~s}$ to move to the starting position (left end). In this system, one relative displacement is obtained per scan and it is defined as that occurring at the middle of each scan interval (7 min and $35 \mathrm{~s}$ ), which is referred to as the scan time. The system was left to run unmanned in accordance with the safety protocol. The data were retrieved on July 3 and analyzed.

We show the distribution of the relative displacement in the COA in Fig. 3. The relative displacement of each area is defined as the average displacement of 10 pixels within the area. The area shaded in red in Fig. 3 exhibited a marked displacement toward the radar during the period of monitoring. We identified several areas that showed distinct displacements, and these areas were termed areas 1-5 ranging near-far from the GB-InSAR instrument (Fig. 3).

The time variations of the relative displacement of each area are shown in Fig. 4 together with the earthquake magnitudes and the cumulative counts of seismic events since June 25 . The same plot is given with a narrower timescale (Fig. 5). No relative displacements could be obtained from 7:26 a.m. (scan time) to 8:12 a.m. (scan time), corresponding to 5 scans (Fig. 5). Although there was no mechanical failure of the system, and the phase variations of the pixels were obtained, no interferogram could be obtained.

At 8:12, a sudden increase in the relative displacements was detected in areas 2 and 3 . The relative displacements continued to increase at a constant rate for approximately $9 \mathrm{~h}$ and reached up to approximately $45 \mathrm{~mm}$. The relative displacement of area 3 then continued to increase with a reduced rate and reached $70 \mathrm{~mm}$ on July 3 . The displacement of area 2 converged to $52 \mathrm{~mm}$ at approximately 9:00 on July 1.

Areas 1, 4, and 5 moved away from the radar. The displacement rates of these areas are found to change at 8:12 a.m. which coincide with the time at which the displacement rates of areas 2 and 3 suddenly increased (Fig. 4).
These blue-shaded areas may be indicative of ground settlement or sliding. The potential for such behavior is inferred from studies indicating that landslides have repeatedly occurred in Owakudani due to the intrinsic weak geomaterials originating from the alterations and weathering processes exerted by the volcano (Takada 1961; Ando and Okubo 1966).

It was difficult to evaluate the error bounds for the reasons stated in the previous section. Authors considered that the irregular undulations of areas 1-5 before the main uplift may be indicative of the atmospheric phase components that could not be removed by the correction plane. The displacements of the time interval, from June 27 10:30 to June 29 0:00, were selected for calculation of standard deviation (STDEV). The time interval was selected such that the variations of the 5 displacements appear unrelated to each other. STDEV of the area 1 to area 5 are: $0.74 \mathrm{~mm}, 0.27 \mathrm{~mm}, 0.27 \mathrm{~mm}, 0.31 \mathrm{~mm}$, $0.53 \mathrm{~mm}$. Visual observations of the displacements in this time interval imply that the residual atmospheric effect is approximately $1-2 \mathrm{~mm}$ which is $3-4$ times the STDEV.

\section{Discussion}

Unfortunately, we are not able to clarify why the GBInSAR interferometry failed at the onset time of the volcanic tremor and the rapid tilt change (7:32 of June 29). Generally, the failure of interferometry can be caused by erratic movements of the antenna or atmospheric effects such as rainfall and gasses. Thus, the ground motion caused by the seismic events after 7:32 may be a candidate for the error since the atmospheric conditions of the period were not adverse compared to the other periods where no interferometry error occurred. However, such intensive earthquakes also took place on morning of June 30 without any interferometry errors (Fig. 4).

We estimated the time at which the relative displacement started to increase, noting that the rates of displacements of areas 2 and 3 appear to be nearly constant, to be from 8:12 to approximately 9:15 (Fig. 5). Lines were fit to the data before $7: 26$ and the data between $8: 12$ and 9:15. The times, corresponding to the intersections of the two sets of fitted lines for areas 2 and 3, are 7:48 and 8:09, respectively (Fig. 5). We thus consider that the uplift started at least before $7: 48$, which is close to the onset (7:32) of the volcanic tremor and rapid tilt change (Yukutake et al. 2017; Honda et al. 2018). These results support the idea that the increase in pressure, caused by the intrusion of hydrothermal fluid, triggered the uplifting of the ground surface of the COA.

The uplifting rate has no significant change at the onset timing of the ash dispersal (at approximately 12:30 on June 29). This observation implies that the release of hydrothermal fluid at this time did not cause significant easing of the 

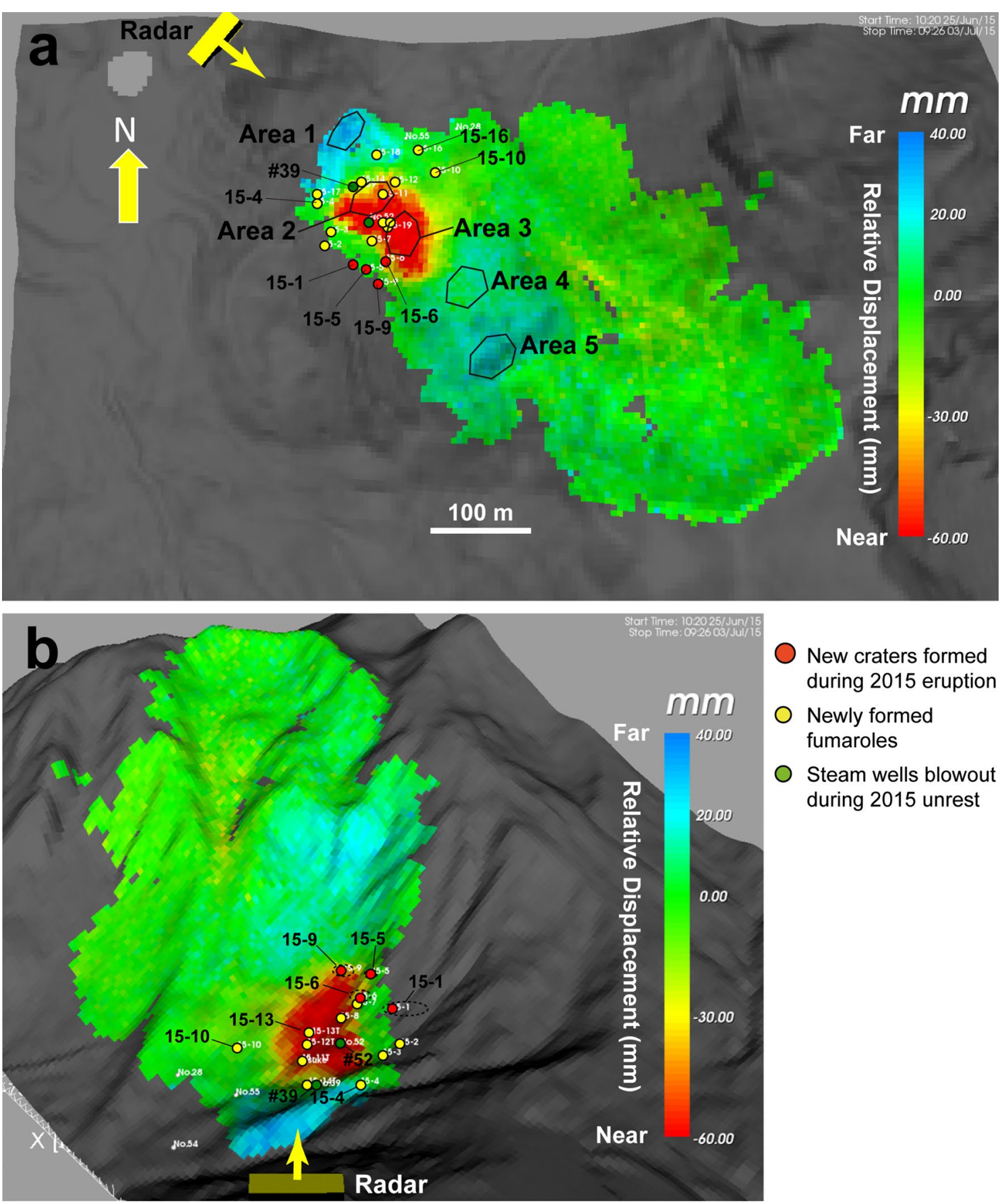

New craters formed during 2015 eruption

Newly formed fumaroles

Steam wells blowout during 2015 unrest

Fig. 3 Cumulative relative displacement for the period from 10:20 a.m. of June 25 to 9:26 a.m. of July 3. $\mathbf{a}$ and $\mathbf{b}$ Bird's-eye view from the radar toward southeast. The negative value (red) in the color bar indicates that the area is moving toward the radar. The positive value in blue indicates that the area is moving away from the radar

underground pressure. The uplifting rate observed by GBInSAR then decreased in two steps. The first deceleration was observed at $16: 18$ on June 29 , and the second deceleration was observed at 8:49 on July 1 (Fig. 4). These decelerations may be explained by the following mechanisms.
At 16:02, an intensive volcanic tremor began, and at 16:37, a major crater was found to have formed (Mannen et al. 2018). Yukutake et al. (2017) proposed that the volcanic tremor radiated from a bursting gas slug on the surface of a volcanic conduit. Thus, the first deceleration 


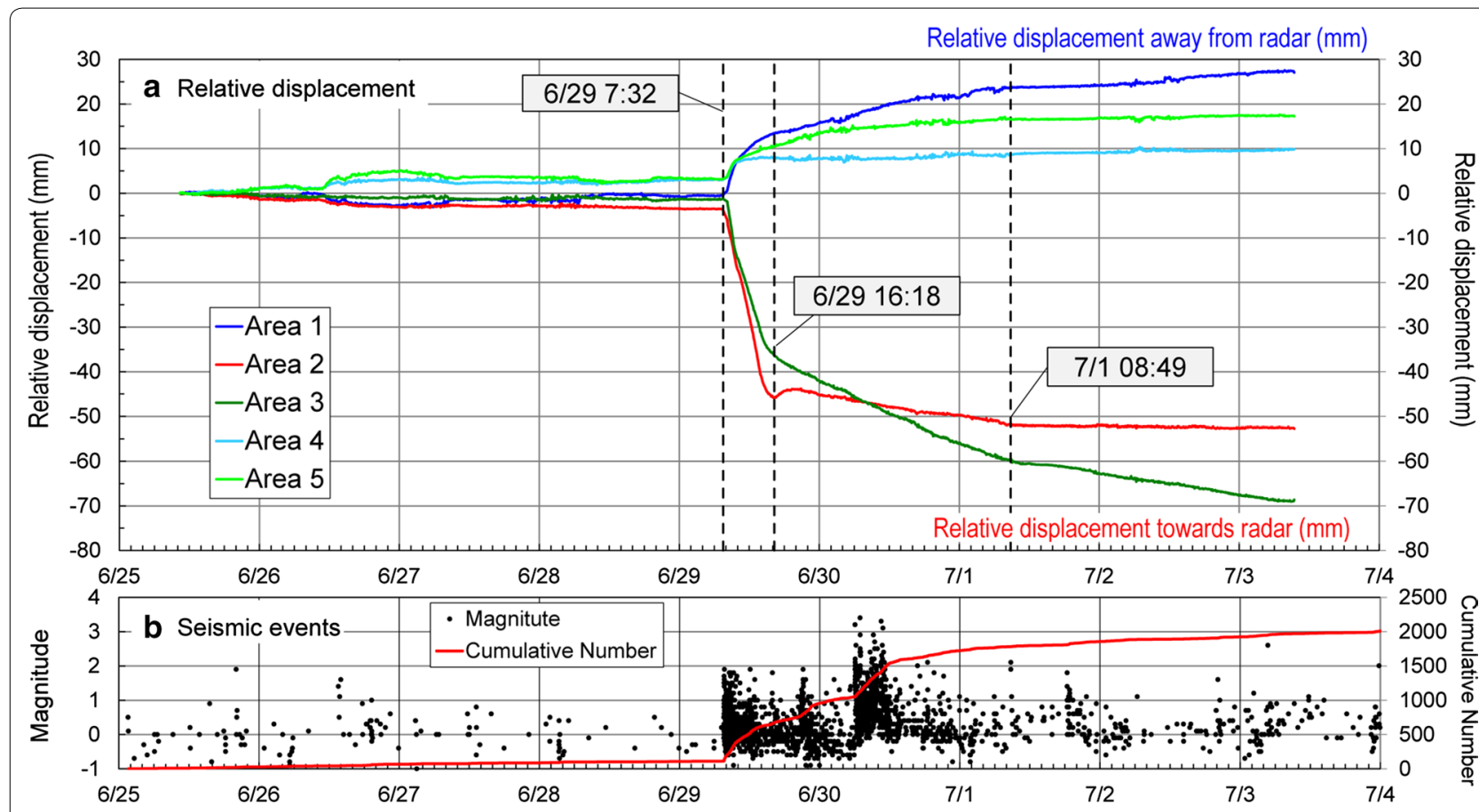

Fig. 4 Time variation of the relative displacements of the five selected areas, magnitude and cumulative number of seismic events. a Time variation of the relative displacements of the five selected areas. Negative displacement implies that the area is moving toward the radar. The vertical interval scale on the time axis starts from 0:00 to 24:00. The time shown as 7:32 a.m. is approximately the time at which the cumulative seismic events exhibited sudden increases. Areas 1-5 are shown in Fig. 3. b Magnitude and cumulative number of seismic events that were determined by Hot Springs Research Institute of Kanagawa Prefecture

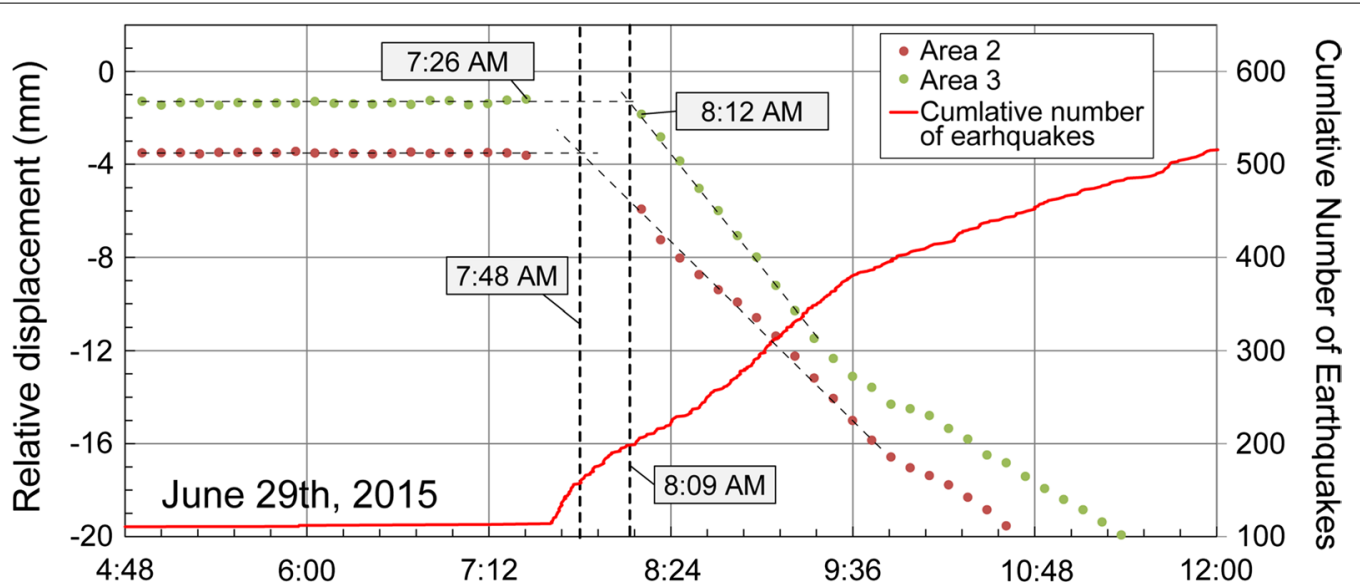

Fig. 5 Close view of the time variations of the relative displacements of two areas (area 2 and area 3 ) and estimated onset of rapid deformation. The time is the morning of June 29. Each data point is plotted at the middle of the scanning interval spanning from the beginning of scan until the beginning of the next scan

of the uplifting rate $(16: 18)$ seemed to reflect a significant release of the underground pressure due to the formation of a stable conduit-crater system that connected the underground hydrothermal system and the surface.

The second deceleration took place at 8:49 on July 1 (Fig. 4). Almost at the same time, the most intensive and longest volcanic tremor was observed, and a new crater was found to have formed (Mannen et al. 2018; Yukutake et al. 2017). These observations imply that the formation of new conduit systems may have released the underground pressure. 
Area 3 continued to uplift until end of the observation. Since area 3 is slightly out of the eruption center, such inflation observed in this area can be interpreted as a weak pressure increase in the very shallow hydrothermal system. Area 1, on the other hand, continued to slowly move away from the radar until the end of the observations. Since this area is landslide prone, the displacement may be interpreted as earthquake-induced slope movements accompanying the eruption.

\section{Conclusions}

We installed a GB-InSAR to monitor the ground deformation of an eruption center area, which was implied by the surface deformation analysis using satellite-based InSAR (Doke et al. 2018). GB-InSAR was installed 4 days before the 2015 eruption of Hakone volcano and captured not only the localized uplifted areas but also the increase and decrease in the ground displacement rates of the uplifted areas both after and during the eruptions. Although there was an interferometry failure for 30 min right after the beginning of the volcanic tremor, the timing of the abrupt increase in the displacement is estimated to be close to the time at which the volcanic tremors and rapid tilt changes were observed for the first time (7:32 a.m.) in the volcanic unrest.

The surface displacement rates of areas 2 and 3 were initially observed $(12-18 \mathrm{~mm} / \mathrm{h})$ and remained approximately constant for approximately $9 \mathrm{~h}$. During this period, ash dispersal and eruption occurred at approximately $12: 30$ p.m. However, no change in the displacement rate was found. Following the rapid deformation stage, deceleration occurred in two steps. These two steps seem to be coincident with the formation of the new conduit system. Thus, it is inferred that the formation of the new conduit systems may have eased the pressure underneath the eruption center.

GB-InSAR has enabled frequent and aerial monitoring of land deformation of the eruption center sites, which were designated as restricted areas due to the uplift detected by InSAR and strong steam emission before the eruption. This unprecedented success demonstrates GBInSAR as a viable method for use in volcanic unrest conditions from a remote and safe area.

\footnotetext{
Abbreviations

GB-InSAR: ground-based interferometric synthetic aperture radar; COA: central Owakudani area; PS: permanent scatterers; SFCW: step frequency continuous wave.

\section{Authors' contributions}

All authors contributed to writing the manuscript. SK and YN performed GBInSAR monitoring and analyzed the results. KM provided the implication of the monitored results in light of potential hydrothermal and eruption mechanisms. RD performed the analysis of datasets obtained by ALOS-2/PALSAR-2
}

and compared the results with the GB-InSAR and seismic data. All authors read and approved the final manuscript.

\section{Author details}

${ }^{1}$ R\&D Center, Nippon Koei Co., Ltd., 2304 Inarihara, Tsukuba, Ibaraki Prefecture, Japan. ${ }^{2}$ Hot Springs Research Institute of Kanagawa Prefecture, 586 Iryuda, Odawara, Kanagawa, Japan.

\section{Acknowledgements}

The authors appreciate Dr. Paolo Farina of Geoapp s.r.l., Firenze Italy and Mr. Francesco, Coppi of IDS GeoRadar s.r.l in Italy for reviewing the technical description of the GB-InSAR. The authors express sincere thanks to Hakone Ropeway Co., Ltd. for allowing and supporting the monitoring at Owakudani Valley.

\section{Competing interests}

The authors declare that they have no competing interests.

\section{Availability of data and materials}

The interferometry data, taken by the GB-InSAR, are readable by the commercial software Guardian (version 3.0), which is made by IDS GeoRadar s.r.l in Italy. The processed displacements can be provided by the corresponding author upon request.

Ethics approval and consent to participate Not applicable.

\section{Funding}

The monitoring was performed by the internal research budget of the authors' affiliations: (1) Research and Development Center, Nippon Koei Co., Ltd. (2) Hot Springs Research Institute of Kanagawa Prefectural Government.

\section{Publisher's Note}

Springer Nature remains neutral with regard to jurisdictional claims in published maps and institutional affiliations.

Received: 6 April 2018 Accepted: 8 November 2018

Published online: 20 November 2018

\section{References}

Ando T, Okubo T (1966) Geological study on the mechanisms of landslides in Owakudani, Kanagawa Prefecture (I). Landslides 3(1):1-24 (in Japanese)

Atzeni C, Barla M, Pieraccini M, Antolini F (2015) Early warning monitoring of natural and engineered slopes with Ground-Based Synthetic Aperture Radar. Rock Mech Rock Eng 48(1):235-246

Barberi F, Bertagnini A, Landi P, Principe C (1992) A review on phreatic eruptions and their precursors. J Volcanol Geotherm Res 52:231-246. https:// doi.org/10.1016/0377-0273(92)90046-G

Bozzano F, Mazzanti P, Prestininzi A (2008) A radar platform for continuous monitoring of a landslide interacting with a under-construction infrastructure. Ital J Eng Geol Environ 2:35-50

Doke R, Harada M, Takenaka J (2015) InSAR analysis of surface displacements in Owakudani associated with the 2015 Hakone Volcanic Activity. Report of Hot Springs Research Institute of Kanagawa Prefecture, vol 47, pp 23-29 (in Japanese)

Doke R, Harada M, Mannen K, Itadera K, Takenaka J (2018) InSAR analysis for detecting the route of hydrothermal fluid to the surface during the 2015 phreatic eruption of Hakone Volcano, Japan. Earth Planets Space 70:63. https://doi.org/10.1186/s40623-018-0834-4

Farina P, Coli N, Yön R, Eken G, Ketizmen H (2013) Efficient real time stability monitoring of mine walls: the Cöllolar mine case study. In: 23rd international mining congress and exhibition of Turkey, Antalya, pp 111-117

Honda R, Yukutake Y, Morita Y, Sakai S, Itadera K, Kokubo K (2018) Precursory tilt changes associated with a phreatic eruption of the Hakone volcano and the corresponding source model. Earth Planets Space 70:117. https://doi. org/10.1186/s40623-018-0887-4 
Mannen K, Doke R, Harada M, Honda R, Itadera K, Kikugawa G, Yukutake Y, Takenaka J (2015) Chronology of the 2015 eruption of Hakone volcano, Japan. In: Abstracts of the Volcanological Society of Japan 2015 Fall Meeting: A3-12 (in Japanese)

Mannen K, Yukutake Y, Kikugawa G, Harada M, Itadera K, Takenaka J (2018) Chronology of the 2015 eruption of Hakone volcano, Japan-geological background, mechanism of volcanic unrest and disaster mitigation measures during the crisis. Earth Planets Space 70:68. https://doi.org/10.1186/ s40623-018-0844-2

Mazzanti P, Bozzano F, Cipriani I, Prestininzi A (2015) New insights into the temporal prediction of landslides by a terrestrial SAR interferometry monitoring case study. Landslides 12:55-68. https://doi.org/10.1007/ s10346-014-0469-x

Monserrat O, Crosetto M, Luzi M (2014) A review of ground-based SAR interferometry for deformation Measurement. ISPRS J Photogram Remote Sens 93(2014):40-48
Rubén I, Xavier F, Lbert A, Jordi M, Carlos L, Josep G, Jordi G (2014) Atmospheric phase screen compensation in ground-based SAR With a multipleregression model over mountainous regions. IEEE Trans Geosci Remote Sens 52(5):2436-2449

Satou Y, Ishizuka T, Kuraoka S, Nakashima Y, Kamijo T (2014) Deformation characteristics of Unzen Lava Dome based on long range displacement monitoring. INTERPREAVENT, Nara

Takada Y (1961) Researches on landslide in Owakudani, Hakone (II). Shin Sabo 13(4):5-7 (in Japanese)

Yukutake Y, Honda R, Harada M, Doke R, Saito T, Ueno T, Sakai S, Morita Y (2017) Analyzing the continuous volcanic tremors detected during the 2015 phreatic eruption of the Hakone volcano. Earth Planets Space 69:164. https://doi.org/10.1186/s40623-017-0751-y

Yukutake Y, Ichihara M, Honda R (2018) Infrasonic wave accompanying a crack opening during the 2015 Hakone eruption. Earth Planets Space 70:53. https://doi.org/10.1186/s40623-018-0820-x

\section{Submit your manuscript to a SpringerOpen ${ }^{\circ}$ journal and benefit from:}

- Convenient online submission

- Rigorous peer review

- Open access: articles freely available online

- High visibility within the field

- Retaining the copyright to your article

Submit your next manuscript at $\boldsymbol{\nabla}$ springeropen.com 